Article

\title{
Identification of Transcriptional Markers and microRNA-mRNA Regulatory Networks in Colon Cancer by Integrative Analysis of mRNA and microRNA Expression Profiles in Colon Tumor Stroma
}

\author{
Md. Nazim Uddin 1,2,3 (D), Mengyuan $\mathrm{Li}^{1,2,3}$ and Xiaosheng Wang 1,2,3,*(D) \\ 1 Biomedical Informatics Research Lab, School of Basic Medicine and Clinical Pharmacy, China Pharmaceutical \\ University, Nanjing 211198, China \\ 2 Cancer Genomics Research Center, School of Basic Medicine and Clinical Pharmacy, China Pharmaceutical \\ University, Nanjing 211198, China \\ 3 Big Data Research Institute, China Pharmaceutical University, Nanjing 211198, China \\ * Correspondence: xiaosheng.wang@cpu.edu.cn
}

Received: 19 July 2019; Accepted: 6 September 2019; Published: 8 September 2019

\begin{abstract}
The aberrant expression of microRNAs (miRNAs) and genes in tumor microenvironment (TME) has been associated with the pathogenesis of colon cancer. An integrative exploration of transcriptional markers (gene signatures) and miRNA-mRNA regulatory networks in colon tumor stroma (CTS) remains lacking. Using two datasets of mRNA and miRNA expression profiling in CTS, we identified differentially expressed miRNAs (DEmiRs) and differentially expressed genes (DEGs) between CTS and normal stroma. Furthermore, we identified the transcriptional markers which were both gene targets of DEmiRs and hub genes in the protein-protein interaction (PPI) network of DEGs. Moreover, we investigated the associations between the transcriptional markers and tumor immunity in colon cancer. We identified 17 upregulated and seven downregulated DEmiRs in CTS relative to normal stroma based on a miRNA expression profiling dataset. Pathway analysis revealed that the downregulated DEmiRs were significantly involved in 25 KEGG pathways (such as TGF- $\beta$, Wnt, cell adhesion molecules, and cytokine-cytokine receptor interaction), and the upregulated DEmiRs were involved in 10 pathways (such as extracellular matrix (ECM)-receptor interaction and proteoglycans in cancer). Moreover, we identified 460 DEGs in CTS versus normal stroma by a meta-analysis of two gene expression profiling datasets. Among them, eight upregulated DEGs were both hub genes in the PPI network of DEGs and target genes of the downregulated DEmiRs. We found that three of the eight DEGs were negative prognostic factors consistently in two colon cancer cohorts, including COL5A2, EDNRA, and OLR1. The identification of transcriptional markers and miRNA-mRNA regulatory networks in CTS may provide insights into the mechanism of tumor immune microenvironment regulation in colon cancer.
\end{abstract}

Keywords: colon tumor stroma; transcriptional markers; prognostic factors; miRNA-mRNA regulatory networks; tumor immune microenvironment

\section{Background}

The tumor microenvironment (TME) is complex "ecosystems" which comprises many different cell types including stromal cells [1]. The functions of stromal cells are often altered in the TME, and the tumor stroma is associated with tumor cellular migration, neoangiogenesis, immunosurveillance evasion, and drug resistance [2]. Colorectal cancer (CRC) is one of the leading causes of cancer mortality worldwide [3]. Transcriptional signatures of CRC stromal cells have been associated with 
poor prognosis in CRC [4-6]. MicroRNAs (miRNAs) play a critical role in modulating the TME in CRC [7]. Bullock et al. showed that stromal and epithelial miRNAs play key roles during CRC progression [8]. Hiyoshi et al. revealed that the elevated expression of miRNAs-34b and -34c in stromal tissues is associated with poor prognosis in colon cancer [9]. These prior studies demonstrated the significant contribution of aberrantly expressed miRNAs in colorectal tumor stroma to CRC growth, invasion, and metastasis.

The miRNA-mRNA interaction networks in cancers have been widely explored. For example, Taguchi et al. identified the potential miRNA-mRNA interactions within multiple cancer types, including colorectal/colon cancer, hepatocellular carcinoma, non-small cell lung cancer, esophageal squamous cell cancer, prostate cancer, and breast cancer [10]. Yang et al. constructed miRNA and mRNA integrative networks as key regulators in colon adenocarcinoma (COAD) [11]. Li et al. built microRNA-mRNA interactions in human colon cancer [12]. Paul et al. identified potential miRNA-mRNA regulatory modules in CRC based on miRNA and mRNA expression data [13]. Sells et al. showed that the tissue kallikrein-related peptidase 6 (KLK6) mediated specific microRNA-mRNA regulatory networks associated with colon cancer invasion [14]. Izadi et al. investigated the conserved mRNA-miRNA interactions in colon and lung cancers [15]. Besides CRC, other cancer-associated miRNA-mRNA interactions have been explored. For example, Pham et al. identified miRNA-mRNA regulatory relationships which were consistent across different breast cancer subtypes [16]. Lou et al. constructed an miRNA-mRNA regulatory network potentially associated with glioblastoma multiforme [17]. These prior studies demonstrated that the miRNA-mRNA regulatory networks play crucial roles in the pathogenesis of cancer. However, the investigation of miRNA-mRNA regulatory networks in the TME, such as tumor stroma, remains lacking.

In this study, using two gene and miRNA expression profiling datasets, we identified differentially expressed miRNAs (DEmiRs) and differentially expressed genes (DEGs) between colon tumor stroma (CTS) and normal stroma. For these DEmiRs, we identified their associated pathways, target genes, and upstream transcriptional regulators. We performed these bioinformatics analyses using several publicly available tools or databases, including miRNet [18], Network Analyst [19], FunRich [20], DIANA-mirPath [21], TargetScan [22], GEPIA [23], PrognoScan [24], TIMER [25], STRING [26], and DGIdb [27]. Furthermore, we evaluated the correlations between the expression levels of the significant genes targeted by DEmiRs and antitumor immune signatures in CTS. Finally, we established a miRNA-mRNA regulatory network potentially associated with colon cancer progression, prognosis, and immune evasion.

\section{Methods}

\subsection{Datasets}

We obtained two CTS gene (or miRNA) expression profiling datasets: GSE31279 (sample size $\mathrm{n}=20)$ [28] and GSE35602 ( $n=17)$ [29] by searching the NCBI gene expression omnibus (GEO) database (https://www.ncbi.nlm.nih.gov/geo/) using the keywords "colon cancer", "stroma", "colon tumor stroma", and "tumor stroma". GSE31279 and GSE35602-GPL6480 $(n=17)$ were used for identifying DEGs and GSE35602-GPL8227 ( $n=17$ ) [29] for identifying DEmiRs between CTS and normal stroma. In addition, we used three CRC gene expression profiling datasets (GSE17536 [30,31], GSE14333 [32], and TCGA COAD) [33] for survival analyses. The TCGA COAD dataset was downloaded from the TCGA data portal (https://portal.gdc.cancer.gov/). The stromal fibroblast cell gene expression profiling dataset GSE46824 $(n=34)$ [34] was downloaded from GEO.

\subsection{Identification of DEGs and DEmiRs between CTS and Normal Stroma}

We used Network Analyst [19] to identify the DEGs between CTS and normal stroma by a meta-analysis of two CTS gene expression profiling datasets (GSE31279 and GSE35602). Each dataset was normalized by quantile normalization. The batch effects from both datasets were removed using 
the ComBat method [35]. We used the R package "limma" to identify the DEGs between CTS and normal stroma, and the Cochran's combination test to perform the meta-analysis [36]. The false discovery rate (FDR) [37] was used to adjust for multiple tests. We identified the DEGs using a threshold of absolute combined effect size (ES) $>1.24$ and FDR $<0.05$. We used miRNet [18] to identify DEmiRs between CTS and normal stroma by analyzing the preprocessed GSE35602-GPL8227. The dataset was normalized by quantile normalization, and the R package "limma" was utilized to identify the DEmiRs between CTS and normal stroma using a threshold of $|\log 2(\mathrm{FC})|>1.0$ and adjusted $p$-value $<0.05$. The "FC" denotes the fold change of mean expression levels between two compared groups.

\subsection{Identification of Upstream Transcription Factors and Target Genes of DEmiRs}

The upstream transcription factors (TFs) regulating DEmiRs were predicted using FunRich [28], a tool for analyzing functional enrichment and interaction network of genes and proteins. The most significant (with the smallest $p$-values) 10 upstream TFs for the upregulated and downregulated DEmiRs were identified, respectively. We used miRNet [18], DIANA-microT-CDS [38], and DIANA-TargetScan [22] to identify target genes of DEmiRs. The online tool "Calculate and draw custom Venn diagrams" (http://bioinformatics.psb.ugent.be/webtools/Venn/) was used to identify common genes between the target genes of DEmiRs and the DEGs between CTS and normal stroma.

\subsection{KEGG Pathway Enrichment Analysis of DEmiRs}

We identified KEGG [39] pathways that were significantly associated with the DEmiRs by DIANA-mirPath (version 3) [21]. In this tool, we chose to analyze the validated miRNA-gene interactions using archive in microT web server v5.0 [38]. A threshold of adjusted $p$-value $<0.05$ (Fisher's exact test) was used to define the statistical significance.

\subsection{Construction of Protein-Protein Interaction (PPI) Network of DEGs}

We constructed a PPI network of the DEGs between CTS and normal stroma by STRING [26]. The hub genes (with no less than 10 edges connected to other nodes) in the PPI network were identified using the node explorer module of Network Analyst [19].

2.6. Comparisons of the Expression Levels of Hub Genes between Colon Cancer and Normal Tissue and Between Colon Tumor Stromal Fibroblast and Normal Fibroblast

We compared the expression levels of the hub genes in the PPI network which were also the targets of the DEmiRs between TCGA COAD and normal tissue, and between colon tumor stromal fibroblast and normal fibroblast. A threshold of Student's $t$ test $p$-value $<0.05$ and $|\mathrm{FC}|>1$ was utilized to denote the statistical significance.

\subsection{Associations of the Expression Levels of the Hub Genes Targeted by DEmiRswith Survival Prognosis in Colon Cancer}

We analyzed the associations of the expression levels of the hub genes targeted by DEmiRs with survival prognosis in colon cancer using PrognoScan [24] and GEPIA [23]. The log-rank test $p$-value $<0.05$ denoted the statistical significance.

\subsection{Associations of the Expression Levels of the Hub Genes Targeted by DEmiRs with Immune Signature Enrichment Levels in Colon Cancer}

We analyzed the correlations of the expression levels of three hub genes (COL5A2, EDNRA, and OLR1) with the abundance of immune signatures in TCGA COAD using TIMER [25]. Moreover, we compared the ratios of pro-inflammatory cytokines to anti-inflammatory cytokines between the colon cancers with high expression levels of the hub genes (expression levels $>$ median) and the colon cancers with low expression levels of the hub genes (expression levels < median) in the TCGA COAD dataset using Student's $t$ test. We defined the ratio of pro-/anti-inflammatory cytokines in a 
tumor sample as the ratio of average expression levels (base-2 log transformed) of their marker genes. The pro-inflammatory cytokines represent the immune-stimulatory signature with marker genes IFNG, $I L-1 A, I L-1 B$, and $I L-2$, and the anti-inflammatory cytokines represent the immune-inhibitory signature with marker genes $I L-4, I L-10, I L-11$, and TGFB1 [40].

\subsection{Identification of Food and Drug Administration (FDA)-Approved Drug-Hub Gene Interaction}

We identified the drugs that target the hub genes using DGIdb [27]. DGIdb collects drug-gene interaction data from 30 disparate sources, including ChEMBL, DrugBank, Ensembl, NCBI Entrez, PharmGKB, PubChem, clinical trial databases, and literature in NCBI PubMed. The drug-gene interactions supported by at least one database and/or PubMed reference were identified. From the identified drug-gene interactions, we selected the drugs that have been approved by the FDA.

\section{Results}

\subsection{Identification of DEmiRs and Their Target DEGs}

We identified seven downregulated and 17 upregulated DEmiRs in CTS relative to colon normal stroma (Table 1). A literature review showed that all seven miRNAs downregulated in CTS have been associated with colon cancer and other cancer types. For example, hsa-mir-135b-5pwas significantly downregulated in CTS with the highest fold change of expression levels (FDR $=0.009$, FC > 7). This miRNA has been associated with gastric carcinogenesis [41]. Hsa-miR-214-3p was significantly downregulated in CTS (FDR $=0.02, \mathrm{FC}>3$ ) and was related to colon cancer risk [42]. Hsa-mir-224-5p was related to the pathogenesis of COAD [11]. Hsa-mir-495-3p might play an important role in the tumorigenesis of glioma [43]. Interestingly, our results showed that hsa-miR-21-5p, hsa-mir-21-3p, and hsa-mir-409-3p were downregulated in CTS, while their expression levels were increased in CRC tissues [44-46].

Table 1. Differentially expressed microRNAs (miRNAs) (DEmiRs) between colon tumor stroma (CTS) and normal stroma and the numbers of their target genes commonly identified by three different tools.

\begin{tabular}{cccc}
\hline miRNA & $\mathbf{L o g}_{2}$ FC $^{\mathbf{a}}$ & FDR $^{\mathbf{b}}$ & Number of Target Genes $^{\mathbf{c}}$ \\
\hline hsa-mir-375 & 2.52 & 0.03 & 48 \\
hsa-mir-551b-3p & 2.33 & 0.009 & NA $^{\mathrm{d}}$ \\
hsa-mir-513c-5p & 2.29 & 0.005 & 2 \\
hsa-mir-192-3p & 2.10 & 0.038 & 15 \\
hsa-mir-215-5p & 2.01 & 0.01 & 27 \\
hsa-mir-192-5p & 1.96 & 0.01 & 37 \\
hsa-mir-378a-3p & 1.76 & 0.01 & 5 \\
hsa-mir-194-5p & 1.74 & 0.04 & 19 \\
hsa-mir-29c-3p & 1.61 & 0.01 & 91 \\
hsa-mir-498 & 1.52 & 0.009 & 28 \\
hsa-mir-194-3p & 1.46 & 0.03 & 8 \\
hsa-mir-29c-5p & 1.38 & 0.008 & NA \\
hsa-mir-10b-5p & 1.31 & 0.01 & 30 \\
hsa-mir-338-3p & 1.31 & 0.01 & 18 \\
hsa-mir-139-5p & 1.28 & 0.01 & 7 \\
hsa-mir-512-3p & 1.09 & 0.01 & 30 \\
hsa-miR-768-3p & 1.09 & 0.02 & NA \\
hsa-mir-135b-5p & -2.81 & 0.009 & 19 \\
hsa-mir-214-3p & -1.66 & 0.02 & 38 \\
hsa-mir-224-5p & -1.60 & 0.01 & 25 \\
hsa-mir-409-3p & -1.30 & 0.04 & 8 \\
hsa-mir-495-3p & -1.22 & 0.01 & 43 \\
hsa-mir-21-5p & -1.15 & 0.04 & 87 \\
hsa-mir-21-3p & -1.08 & 0.01 & 6 \\
\hline
\end{tabular}

${ }^{a}$ FC: fold change; ${ }^{b}$ FDR: false discovery rate; ${ }^{c}$ The number of miRNA target genes which were commonly identified by miRNet [18], MicroT-CDS [38], and TargetScan [22]. ${ }^{\mathrm{d}}$ NA: not available. 
Many of the significantly upregulated DEmiRs in CTS have been associated with CRC. For example, the expression levels of hsa-mir-375 were 5.74 times higher in CTS than in normal stroma $(p=0.03)$. This miRNA was also differentially expressed between CRC and normal tissue [47]. Hsa-mir-192-3p was enriched in different extracellular vesicle subtypes derived from CRC cell lines [48]. The elevated expression of hsa-mir-215-5pwas associated with CRC metastasis [49]. Hsa-mir-378a-3pwas differentially expressed between human colorectal carcinoma and normal colonic mucosa [50]. The analysis of circulating miRNA expression profiles revealed that hsa-mir-498was upregulated in colon cancer patients [46].

Therefore, a majority of the aberrantly expressed DEmiRs in CTS relative to normal stroma identified by the bioinformatics approach have been related to the pathogenesis of colon cancer.

\subsection{Identification of Upstream TFs and Genes Significantly Associated with the DEmiRs}

We used FunRich [20] to identify upstream TFs regulating the DEmiRs. For the upregulated DEmiRs, the most significant 10 upstream TFs included EGR1, SP1, SP4, NKX6-1, POU2F1, MEF2A, RREB1, ZFP161, NFIC, and ONECUT1 (Table 2). For the downregulated DEmiRs, the most significant 10 TFs included SP4, SP1, EGR1, HOXA5, PDX1, KLF7, RORA, POU2F1, TCF3, and FOXD3 (Table 2). Previous studies have revealed that most of the upstream TFs are related to CRC. For example, SP1 regulating most of the upregulated DEmiRs has been associated with colon tumor adhesion, migration and invasion [51]. SP1 and SP4 are essential for colon cancer cells and knockdown of them may induce apoptosis in cancer cells [52]. EGR1can promote proliferation of colon cancer cells via the EGR1/AE2/P16/P-ERK signaling pathway [53]. POU2F1 is involved in the regulation of colon malignancy [54]. TCF3 has been identified as an upstream TF of CTS-specific transcriptional signatures [55]. FOXD3 plays an important role in inhibiting colon cancerogenesis by regulating EGFR/Ras/Raf/MEK/ERK signaling pathway [56].

Furthermore, we predicted target genes of DEmiRs using three different tools (miRNet [18], MicroT-CDS [38], and TargetScan [22]) (Supplementary Tables S1-S3), and obtained the common target genes predicted by the three tools. We identified 2056 DEmiR-gene regulation relationships based on these DEmiRs using miRNet [18], MicroT-CDS [38] and TargetScan [22]. In total, 1021 and 620 genes were predicted as targets of the upregulated and downregulated DEmiRs, respectively.

Table 2. The most significant 10 upstream transcription factors (TFs) regulating the upregulated DEmiRs and the most significant 10 upstream TFs regulating the downregulated DEmiRs.

\begin{tabular}{ccc}
\hline Change of DEmiRs & Upstream TFs & $p$-Value (Hypergeometric Test) \\
\hline & EGR1 & $6.50 \times 10^{-37}$ \\
\cline { 2 - 3 } & SP1 & $5.36 \times 10^{-29}$ \\
\cline { 2 - 3 } Upregulated & SP4 & $6.01 \times 10^{-26}$ \\
\cline { 2 - 3 } & NKX6-1 & $5.19 \times 10^{-22}$ \\
\cline { 2 - 3 } & POU2F1 & $3.44 \times 10^{-21}$ \\
\cline { 2 - 3 } & MEF2A & $3.64 \times 10^{-18}$ \\
\hline & RREB1 & $1.41 \times 10^{-17}$ \\
\hline & ZFP161 & $1.94 \times 10^{-16}$ \\
\hline & NFIC & $2.61 \times 10^{-15}$ \\
\hline
\end{tabular}


Table 2. Cont.

\begin{tabular}{lcc}
\hline Change of DEmiRs & Upstream TFs & $p$-Value (Hypergeometric Test) \\
\hline & SP4 & $1.30 \times 10^{-17}$ \\
\cline { 2 - 3 } & SP1 & $3.82 \times 10^{-17}$ \\
\cline { 2 - 3 } Downregulated & EGR1 & $3.85 \times 10^{-15}$ \\
\cline { 2 - 3 } & HOXA5 & $1.43 \times 10^{-8}$ \\
\cline { 2 - 3 } & PDX1 & $1.92 \times 10^{-8}$ \\
\cline { 2 - 3 } & KLF7 & $3.18 \times 10^{-8}$ \\
\cline { 2 - 3 } & RORA & $3.62 \times 10^{-8}$ \\
\hline & POU2F1 & $9.19 \times 10^{-8}$ \\
\hline & TCF3 & $3.27 \times 10^{-7}$ \\
\hline
\end{tabular}

\subsection{Identification of Pathways Significantly Associated with DEmiRs}

We identified 25 KEGG [39] pathways significantly associated with the downregulated DEmiRs in CTS using DIANA-miRPath [21]. These pathways are mainly involved in cancer (pathways in cancer, pancreatic cancer, and proteoglycans in cancer), cellular development (cell adhesion molecules, Wnt, TGF- $\beta$, FoxO, adherens junction, Gap junction, and ErbB pathways), immune regulation (cytokine-cytokine receptor interaction), and metabolism (glycosphingolipid biosynthesis-lacto and neolacto series, biosynthesis of unsaturated fatty acids, and ubiquitin mediated proteolysis) (Supplementary Table S4). Previous studies have shown that some of these pathways are significantly associated with colon cancer or CTS. For example, the Wnt signaling, cell adhesion molecules, adherens junction, gap junction, and cytokine-cytokine receptor interaction pathways have been associated with CTS [6]. Genetic variation in the TGF- $\beta$ signaling pathway may lead to an increased risk of CRC [57]. ErbB signaling pathway is involved in cell proliferation, invasion, metastasis, and neoangiogenesis in colon cancer [58]. Moreover, we identified 10 KEGG pathways that were significantly associated with the upregulated DEmiRs in CTS (Supplementary Table S5). Many of these pathways have been associated with colon cancer. For example, the extracellular matrix (ECM)-receptor interaction pathway is highly enriched in CTS [6]. Dysregulation of proteoglycans is associated with colon cancer prognosis [59].

\subsection{Identification of Differentially Expressed Hub Genes Targeted by DEmiRs}

We identified 460 DEGs between CTS and normal stroma by a meta-analysis of two GEO microarray datasets (GSE31279 andGSE35602). These DEGs included 160 downregulated and 300 upregulated genes in CTS (Supplementary Tables S6 and S7). Based on the 460 DEGs, we constructed a PPI network to identify hub genes (Supplementary Table S8) and found eight hub genes (degree $\geq 10$ ) targeted by the DEmiRs (Figure 1A). All the eight genes (COL5A2, EDNRA, OLR1, TGFBI, MET, TNFRSF11B, TWIST1, and WNT5A) were upregulated in CTS and were targeted by the downregulated DEmiRs (Figure 1B). COL5A2 is predominantly expressed in COAD stroma [60]. A meta-analysis of gene expression profiles in 950 cancer cell lines revealed that OLR1 was upregulated in $20 \%$ of CRC cells [61]. 
A

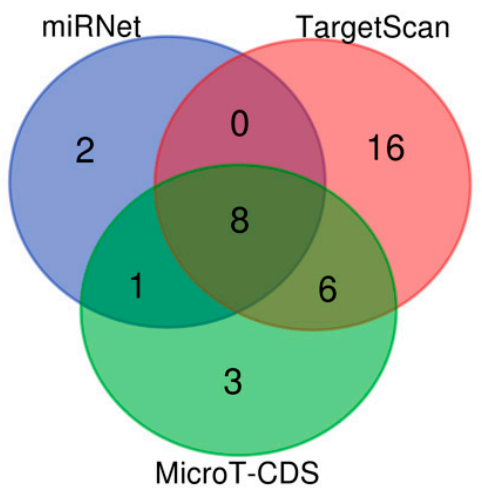

B

\begin{tabular}{|c|c|c|c|c|c|}
\hline Hub gene & Combined ES & $\begin{array}{c}\text { Adjusted } P \\
\text { value }\end{array}$ & $\begin{array}{c}\text { PPI } \\
\text { degree }\end{array}$ & MiRNA regulator & $\begin{array}{c}\text { Log2 FC of } \\
\text { DEmiRs }\end{array}$ \\
\hline \multirow{2}{*}{ WNT5A } & \multirow{2}{*}{1.6704} & \multirow{2}{*}{0.007} & \multirow[t]{2}{*}{25} & hsa-mir-21-5p & -1.15 \\
\hline & & & & hsa-miR-495-3p & -1.22 \\
\hline \multirow[t]{4}{*}{ COL5A2 } & \multirow[t]{4}{*}{2.131} & \multirow[t]{4}{*}{0.003} & \multirow[t]{4}{*}{21} & hsa-mir-21-5p & -1.15 \\
\hline & & & & hsa-miR-495-3p & -1.22 \\
\hline & & & & hsa-miR-135b-5p & -2.81 \\
\hline & & & & hsa-miR-409-3p & -1.30 \\
\hline \multirow[t]{2}{*}{ TWIST1 } & \multirow[t]{2}{*}{1.6199} & \multirow[t]{2}{*}{0.007} & \multirow[t]{2}{*}{19} & hsa-mir-214-3p & -1.66 \\
\hline & & & & hsa-miR-409-3p & -1.30 \\
\hline \multirow[t]{2}{*}{ MET } & \multirow[t]{2}{*}{1.9446} & \multirow[t]{2}{*}{0.001} & \multirow[t]{2}{*}{16} & hsa-mir-409-3p & -1.30 \\
\hline & & & & hsa-miR-495-3p & -1.22 \\
\hline \multirow[t]{2}{*}{ OLR1 } & \multirow[t]{2}{*}{1.3623} & \multirow[t]{2}{*}{0.028} & \multirow[t]{2}{*}{13} & hsa-mir-21-5p & -1.15 \\
\hline & & & & hsa-miR-409-3p & -1.30 \\
\hline \multirow[t]{3}{*}{ TNFRSF11B } & \multirow[t]{3}{*}{1.3015} & \multirow[t]{3}{*}{0.038} & \multirow[t]{3}{*}{12} & hsa-mir-21-5p & -1.15 \\
\hline & & & & hsa-miR-135b-5p & -2.81 \\
\hline & & & & hsa-miR-224-5p & -1.60 \\
\hline \multirow[t]{3}{*}{$T G F B I$} & \multirow[t]{3}{*}{2.1236} & \multirow[t]{3}{*}{0.0008} & \multirow[t]{3}{*}{11} & hsa-mir-21-5p & -1.15 \\
\hline & & & & hsa-miR-214-3p & -1.66 \\
\hline & & & & hsa-miR-409-3p & -1.30 \\
\hline \multirow[t]{4}{*}{ EDNRA } & \multirow[t]{4}{*}{2.6405} & \multirow[t]{4}{*}{0.035} & \multirow[t]{4}{*}{11} & hsa-mir-224-5p & -1.60 \\
\hline & & & & hsa-miR-135b-5p & -2.81 \\
\hline & & & & hsa-miR-495-3p & -1.22 \\
\hline & & & & hsa-miR-21-3p & -1.08 \\
\hline
\end{tabular}

Figure 1. Identification of hub genes targeted by DEmiRs. (A) A total of eight hub genes were identified as the targets of downregulated DEmiRs in CTS which were commonly predicted by all three different tools (miRNet [18], MicroT-CDS [38], and TargetScan [22]). (B) A detailed description of the eight hub genes and their associated regulatory DEmiRs. ES: effect size. FDR: false discovery rate.

Interestingly, we found that all eight hub genes (COL5A2, EDNRA, TGFBI, MET, OLR1, TNFRSF11B, TWIST1, and WNT5A) were also upregulated in TCGA COAD samples versus normal samples (Student's $t$ test, $p<0.001$ ) (Figure 2). It indicates that stromal components may have a contribution to COAD transcriptome. However, none of the hub genes showed significant expression differences between colon tumor stromal fibroblast and normal fibroblast (Supplementary Table S9), suggesting that these hub genes are specifically expressed in other CTS cells. 

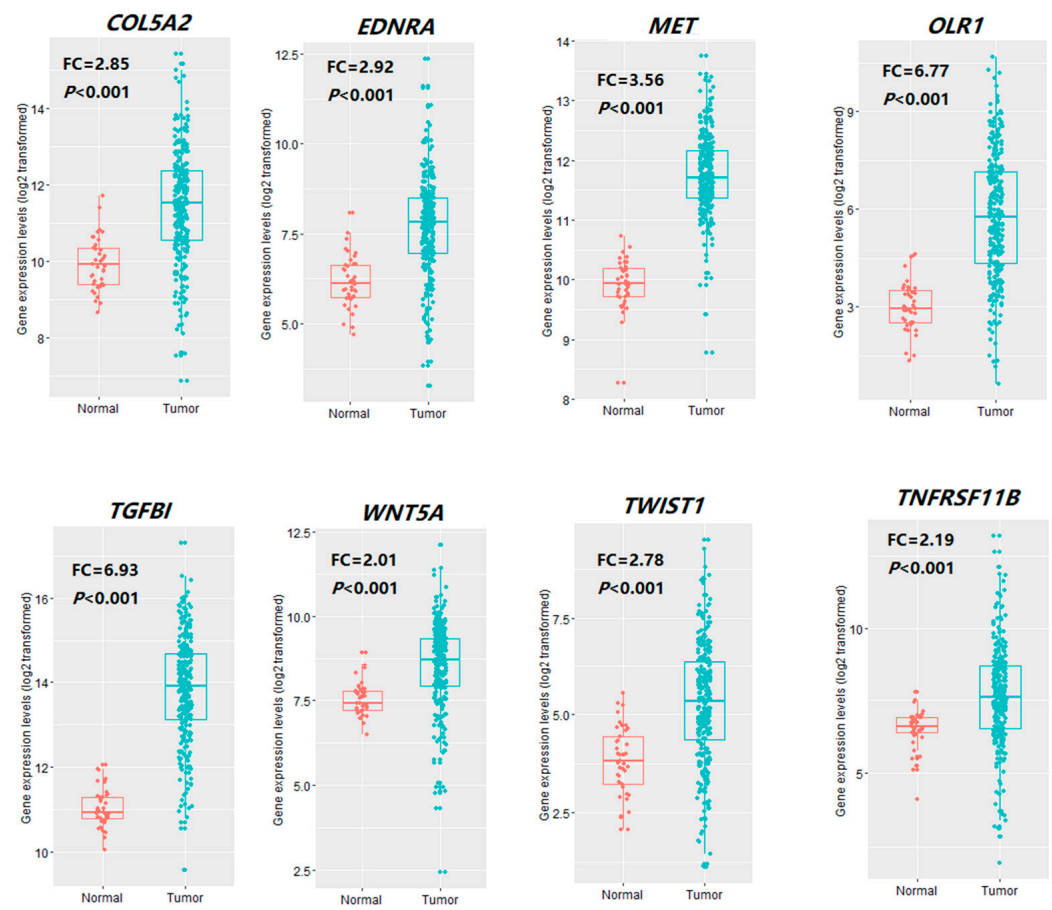

Figure 2. Comparisons of the expression levels of the eight hub genes between TCGA colon cancer and normal tissue. COL5A2, EDNRA, TGFBI, MET, OLR1, TNFRSF11B, TWIST1, and WNT5A are upregulated in colon cancer versus normal samples (Student's $t$ test, $p<0.001$ ). FC: Fold change.

\subsubsection{The Hub Genes Are Negative Prognostic Factors in CRC}

Survival analyses using Prognoscan [24] showed that three hub genes (COL5A2, EDNRA, and OLR1) had a negative expression correlation with survival prognosis (overall survival (OS) and/or disease-free survival (DFS)) in CRC (Figure 3A). Moreover, the elevated expression of COL5A2, EDNRA, TGFBI, and OLR1 was associated with a worse DFS prognosis in TCGA COAD (Figure 3B). Previous studies have shown that some of the hub genes are associated with prognosis in colon cancer. For example, the depressed expression of EDNRA is associated with a better prognosis in colon cancer [62]. Taken together, these data demonstrate that the upregulated hub genes regulated by the downregulated DEmiRs in CTS are negative prognostic factors in colon cancer.
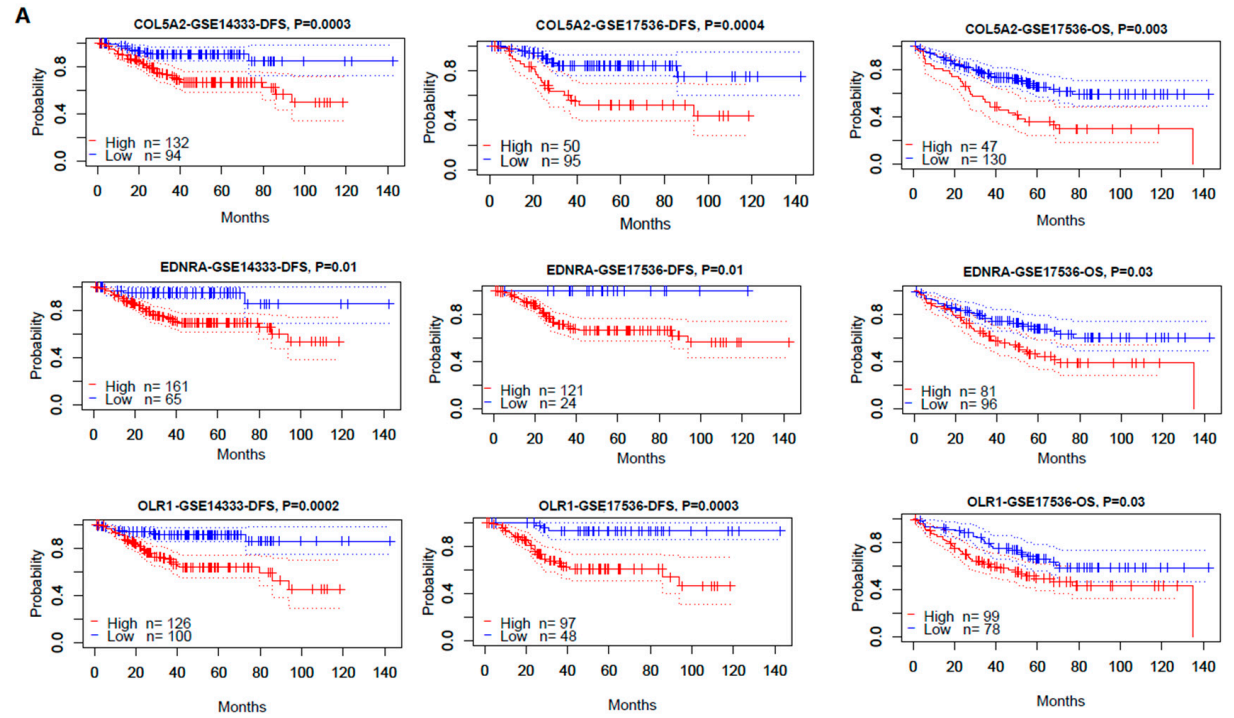

Figure 3. Cont. 

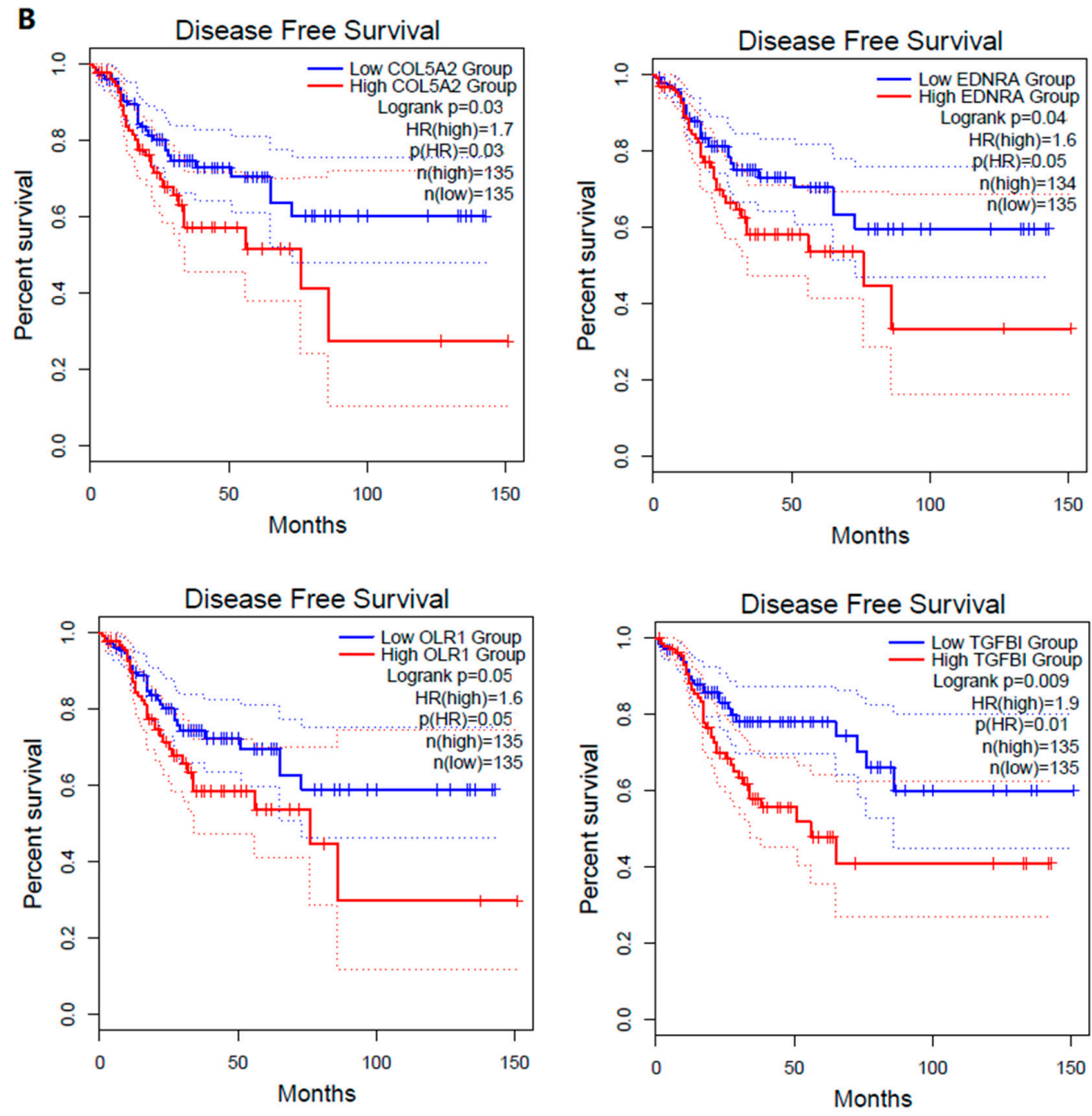

Figure 3. Associations of the expression of hub genes with survival prognosis in colorectal cancer (CRC) patients. (A). Kaplan-Meier curves show that three hub genes (COL5A2, EDNRA, and OLR1) had a negative expression correlation with survival prognosis (overall survival (OS) and/or disease-free survival (DFS)) in CRC by Prognoscan (log-rank test, $p<0.05)$. (B). Kaplan-Meier curves shows that the elevated expression of four hub genes (COL5A2, EDNRA, OLR1, and TGFBI) is associated with a worse DFS prognosis in the TCGA colon cancer cohort by GEPIA [23] (log-rank test, $p<0.05$ ).

3.4.2. The Elevated Expression of Hub Genes Is Associated with the Immunosuppressive TME in Colon Cancer

The tumor-infiltrating lymphocytes (TILs) level is an independent predictor of survival in CRC [63]. We analyzed the correlations between the expression levels of three hub genes and the levels of TILs in TCGA COAD. The three hub genes included COL5A2, EDNRA, and OLR1 which were identified as negative prognostic factors in both TCGA COAD [33] and two microarray CRC cohorts (GSE17536 [30,31] and GSE14333) [32]. Interestingly, we found that the elevated expression of the three genes was consistently correlated with the upregulation of immunosuppressive signatures in colon cancer, such as tumor-associated macrophages (TAMs), M2 macrophages, regulatory T cells (Tregs), and $\mathrm{T}$ cell exhaustion (Table 3). Moreover, the expression levels of the three genes exhibited significant positive correlations with the expression levels of immune-inhibitory marker genes, including PD-L1, PD-L2, TGFB1, and TGFBR1 (Figure 4A). Interestingly, we found that the ratios of pro-/anti-inflammatory cytokines were significantly lower in the colon cancers highly expressing the hub genes (expression levels $>$ median) than in those lowly expressing the hub genes (expression levels $<$ median) in the 
TCGA COAD cohort (Student's $t$ test, $p<0.001$ ) (Figure 4B). Altogether, these results suggest that the elevated expression of these hub genes is associated with the immunosuppressive TME in colon cancer that could explain their oncogenic function to a certain degree.
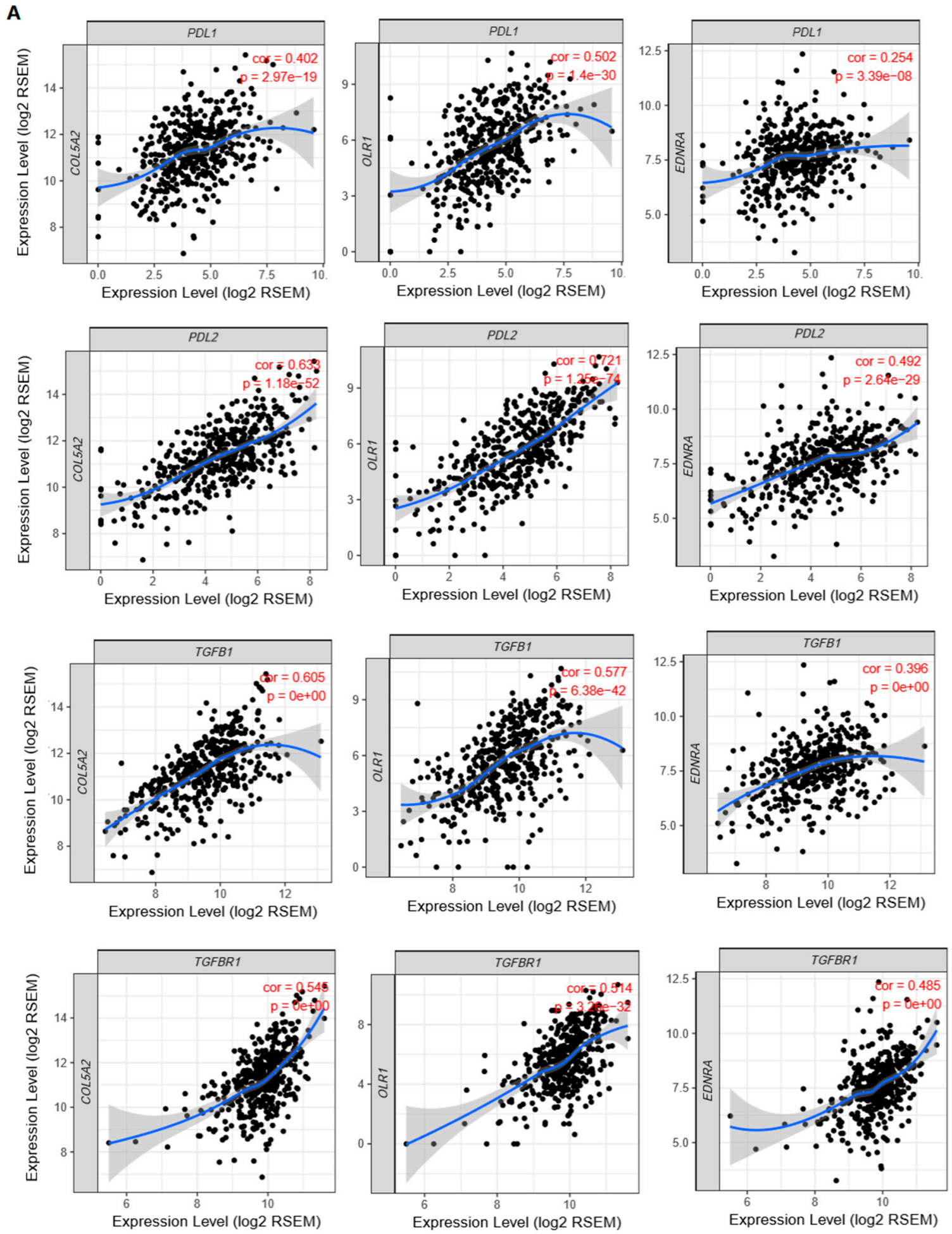

Figure 4. Cont. 
B

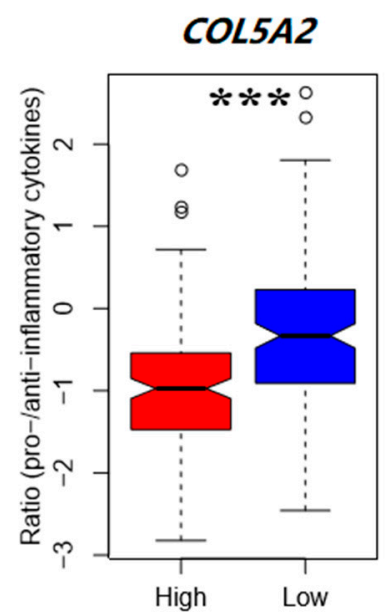

EDNRA

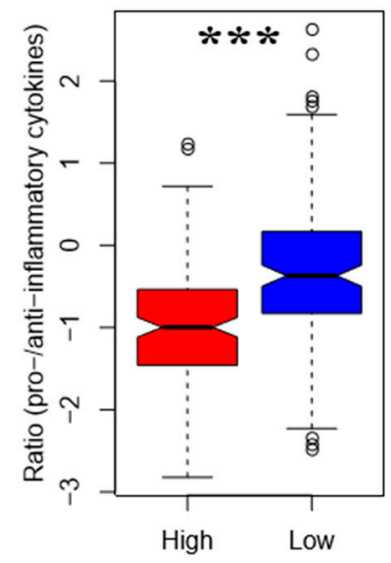

OLR1

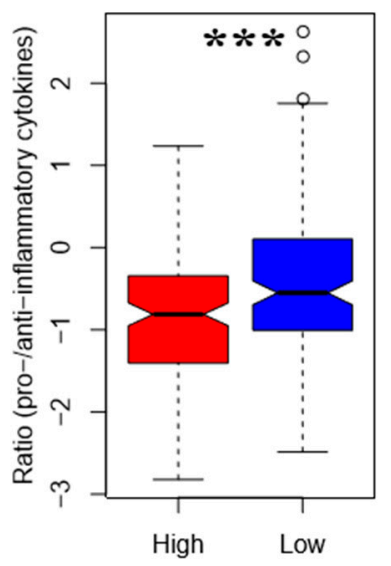

Figure 4. Associations between hub genes and immune signatures in colon cancer. (A) Three hub genes (COL5A2, EDNRA, and OLR1) exhibit a significant positive expression correlation with four immune-inhibitory marker genes (PD-L1, $P D-L 2, T G F B 1$, and TGFBR1). The correlation analyses were performed using TIMER [25]. The Spearman's correlation test $p$-values ( $p$ ) and correlation coefficients (cor) are shown. RSEM: RNA-Seq by Expectation Maximization [64]. (B) The ratios of pro-/anti-inflammatory cytokines are significantly lower in the colon cancers highly expressing the hub genes (expression levels $>$ median) than in those lowly expressing the hub genes (expression levels $<$ median) in the TCGA COAD cohort (Student's $t$ test, $p<0.001$ ). The ratio of pro-/anti-inflammatory cytokines in a tumor sample is defined as the ratio of average expression levels (log2-transformed) of their marker genes. The pro-inflammatory cytokines represent the immune-stimulatory signature with marker genes IFNG, $I L-1 A, I L-1 B$, and $I L-2$, and the anti-inflammatory cytokines represent the immune-inhibitory signature with marker genes IL-4, IL-10, IL-11, and TGFB1 [40]. ***, $p<0.001$.

Table 3. Expression correlations between three hub genes and marker genes of immune-inhibitory signatures evaluated by TIMER [25].

\begin{tabular}{|c|c|c|c|c|c|c|c|}
\hline \multirow{2}{*}{$\begin{array}{l}\text { Immune } \\
\text { Signature }\end{array}$} & \multirow{2}{*}{$\begin{array}{c}\text { Marker } \\
\text { Gene }\end{array}$} & \multicolumn{2}{|c|}{ COL5A2 } & \multicolumn{2}{|c|}{ EDNRA } & \multicolumn{2}{|c|}{ OLR1 } \\
\hline & & cor & $p$ & cor & $p$ & cor & $p$ \\
\hline \multirow{2}{*}{ Monocyte } & CD86 & 0.629 & $7.81 \times 10^{-52}$ & 0.492 & $2.47 \times 10^{-29}$ & 0.78 & $8.21 \times 10^{-95}$ \\
\hline & CD115 & 0.601 & $<1 \times 10^{-100}$ & 0.448 & $<1 \times 10^{-100}$ & 0.618 & $1.34 \times 10^{-49}$ \\
\hline \multirow{3}{*}{ TAM } & CCL2 & 0.645 & $<1 \times 10^{-100}$ & 0.593 & $<1 \times 10^{-100}$ & 0.686 & $6.35 \times 10^{-65}$ \\
\hline & CD68 & 0.42 & $<1 \times 10^{-100}$ & 0.243 & $1.47 \times 10^{-7}$ & 0.494 & $1.59 \times 10^{-29}$ \\
\hline & IL10 & 0.427 & $1 \times 10^{-21}$ & 0.359 & $2.15 \times 10^{-15}$ & 0.537 & $1.61 \times 10^{-35}$ \\
\hline \multirow{3}{*}{$\begin{array}{c}\text { M2 } \\
\text { Macrophage }\end{array}$} & CD163 & 0.667 & $2.9 \times 10^{-60}$ & 0.481 & $6.39 \times 10^{-28}$ & 0.741 & $5.84 \times 10^{-81}$ \\
\hline & VSIG4 & 0.588 & $<1 \times 10^{-100}$ & 0.462 & $<1 \times 10^{-100}$ & 0.729 & $3.86 \times 10^{-77}$ \\
\hline & $M S 4 A 4 A$ & 0.575 & $1.34 \times 10^{-41}$ & 0.475 & $4.2 \times 10^{-27}$ & 0.74 & $1.92 \times 10^{-80}$ \\
\hline \multirow{3}{*}{ Th1 } & T-bet & 0.321 & $2.02 \times 10^{-12}$ & 0.175 & $1.73 \times 10^{-4}$ & 0.369 & $3.39 \times 10^{-16}$ \\
\hline & $I F N-\gamma$ & 0.176 & $1.55 \times 10^{-4}$ & 0.1 & $3.32 \times 10^{-2}$ & 0.325 & $9.92 \times 10^{-13}$ \\
\hline & $T N F-\alpha$ & 0.314 & $6.3 \times 10^{-12}$ & 0.248 & $7.32 \times 10^{-8}$ & 0.375 & $9.92 \times 10^{-17}$ \\
\hline \multirow{3}{*}{ Treg } & FOXP3 & 0.496 & $<1 \times 10^{-100}$ & 0.358 & $3.57 \times 10^{-15}$ & 0.468 & $2.79 \times 10^{-26}$ \\
\hline & CCR8 & 0.537 & $1.61 \times 10^{-35}$ & 0.406 & $1.34 \times 10^{-19}$ & 0.535 & $2.51 \times 10^{-35}$ \\
\hline & TGFB1 & 0.605 & $<1 \times 10^{-100}$ & 0.396 & $<1 \times 10^{-100}$ & 0.577 & $6.38 \times 10^{-42}$ \\
\hline
\end{tabular}


Table 3. Cont.

\begin{tabular}{cccccccc}
\hline \multirow{2}{*}{$\begin{array}{c}\text { Immune } \\
\text { Signature }\end{array}$} & $\begin{array}{c}\text { Marker } \\
\text { Gene }\end{array}$ & \multicolumn{2}{c}{ COL5A2 } & \multicolumn{2}{c}{ EDNRA } & \multicolumn{2}{c}{ OLR1 } \\
\cline { 2 - 7 } & cor & $p$ & cor & $p$ & cor & $p$ \\
\hline & PD-1 & 0.268 & $5.8 \times 10^{-9}$ & 0.106 & $2.39 \times 10^{-2}$ & 0.333 & $2.6 \times 10^{-13}$ \\
\cline { 2 - 7 } & CTLA4 & 0.375 & $9.02 \times 10^{-17}$ & 0.274 & $2.59 \times 10^{-9}$ & 0.43 & $4.53 \times 10^{-22}$ \\
\cline { 2 - 7 } $\begin{array}{c}\text { T cell } \\
\text { exhaustion }\end{array}$ & LAG3 & 0.258 & $2.44 \times 10^{-8}$ & 0.109 & $1.99 \times 10^{-2}$ & 0.359 & $2.28 \times 10^{-15}$ \\
\cline { 2 - 7 } & TIM-3 & 0.625 & $<1 \times 10^{-100}$ & 0.469 & $<1 \times 10^{-100}$ & 0.788 & $3.58 \times 10^{-98}$ \\
\cline { 2 - 7 } & TIGIT & 0.408 & $8.6 \times 10^{-20}$ & 0.243 & $1.36 \times 10^{-7}$ & 0.493 & $1.8 \times 10^{-29}$ \\
\cline { 2 - 7 } & CXCL13 & 0.365 & $7.39 \times 10^{-16}$ & 0.245 & $1.04 \times 10^{-7}$ & 0.494 & $1.54 \times 10^{-29}$ \\
\cline { 2 - 7 } & LAYN & 0.766 & $1.75 \times 10^{-89}$ & 0.636 & $2.4 \times 10^{-53}$ & 0.7 & $1.08 \times 10^{-68}$ \\
\hline
\end{tabular}

cor: Spearman's rank correlation coefficient; $p$ : $p$-value (Spearman's correlation test).

\subsection{Identification of Candidate Drugs Targeting Hub Genes}

Using DGIdb [27], we identified eight FDA-approved drugs that potentially target the protein products of two hub genes (EDNRA and COL5A2) (Table 4). Table 4 shows that the drugs targeting EDNRA are mostly antagonists. EDNRA (Endothelin receptor) antagonists ambrisentan, bosentan, and macitentan have been evaluated as hepatobiliary transporter inhibitors and substrates in sandwich-cultured human hepatocytes [65]. The efficacy of macitentan, a dual endothelin receptor antagonist, has been evaluated in treating the brain metastases of breast and lung cancers in mice [66]. The use of macitentan, a dual endothelin receptor antagonist, in combination with temozolomide, may lead to glioblastoma regression and long-term survival in mice [67]. Nevertheless, to our knowledge, inhibition of EDNRA or COL5A2 has not been tested for colon cancer treatment. Our data suggest that these genes could be promising targets for development of anticancer drugs in treating colon cancer patients.

Table 4. Eight FDA-approved drugs potentially targeting three hub genes.

\begin{tabular}{cccc}
\hline Drug & Target Gene & Interaction Types & Score $^{\mathbf{d}}$ \\
\hline ambrisentan & $E D N R A$ & antagonist & 9 \\
\hline aspirin & $E D N R A$ & NA & 2 \\
\hline guanfacine & $E D N R A$ & antagonist & 1 \\
\hline cefadroxil & $E D N R A$ & antagonist & 1 \\
\hline bosentan & $E D N R A$ & antagonist & 11 \\
\hline macitentan & $E D N R A$ & antagonist & 7 \\
\hline collagenase clostridium histolyticum & COL5A2 & NA & 1 \\
\hline ocriplasmin & COL5A2 & NA & 1 \\
\hline
\end{tabular}

\footnotetext{
$\mathrm{d}$ The score is the number of database sources and/or PubMed references supporting the drug-gene interaction.
}

\section{Discussion}

For the first time, we built the miRNA-mRNA regulatory network based on the aberrantly expressed miRNAs and genes in CTS. We identified seven downregulated and 17 upregulated DEmiRs in CTS relative to normal stroma by a meta-analysis. A recent study has revealed that TFs can modulate the expression of miRNAs, and they have a synthetic effect on the expression of their common target genes in colon cancer [68]. Thus, we identified upstream TFs that potentially regulated the DEmiRs. Notably, SP1, a zinc finger TF, potentially regulated a majority of the DEmiRs. Pathway enrichment analysis revealed that these DEmiRs were significantly associated with the pathways involved in cancer, cellular development, immune regulation, and metabolism. Furthermore, we identified 
DEGs between CTS and normal stroma and constructed a PPI network of these DEGs. From the PPI network, we identified eight hub genes which were significantly upregulated in CTS and were targeted by the downregulated DEmiRs. Among the eight hub genes, three (COL5A2, EDNRA, and OLR1) showed significant inverse expression correlations with OS and/or DFS in three CRC cohorts (Figure 3). Moreover, the elevated expression of the three prognostic hub genes (PHGs) was significantly correlated with immunosuppressive signatures in colon cancer (Figure 4). Network analysis showed that many immune-inhibitory signature genes interacted with the PHGs (Figure 5A). For example, OLR1 interected with CCL2 and CD68. These results suggest that the negative prognostic impact of PHGs in colon cancer may result from the suppressive antitumor immune microenvironment. Collectively, the expression pattern, prognostic effect, immune-inhibitory activity demonstrated the oncogenic effect of COL5A2, EDNRA, and OLR1 in colon cancer.

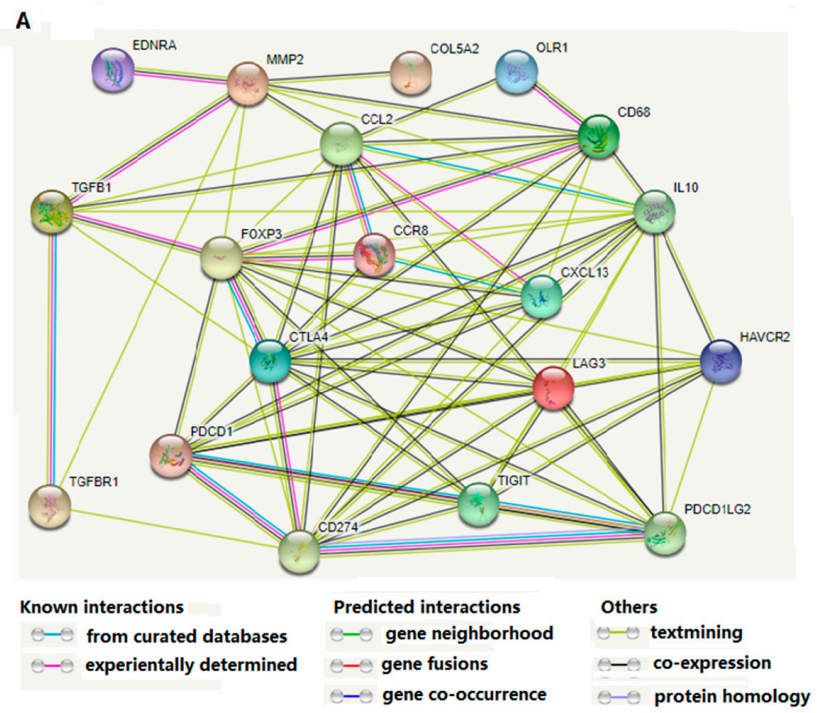

B

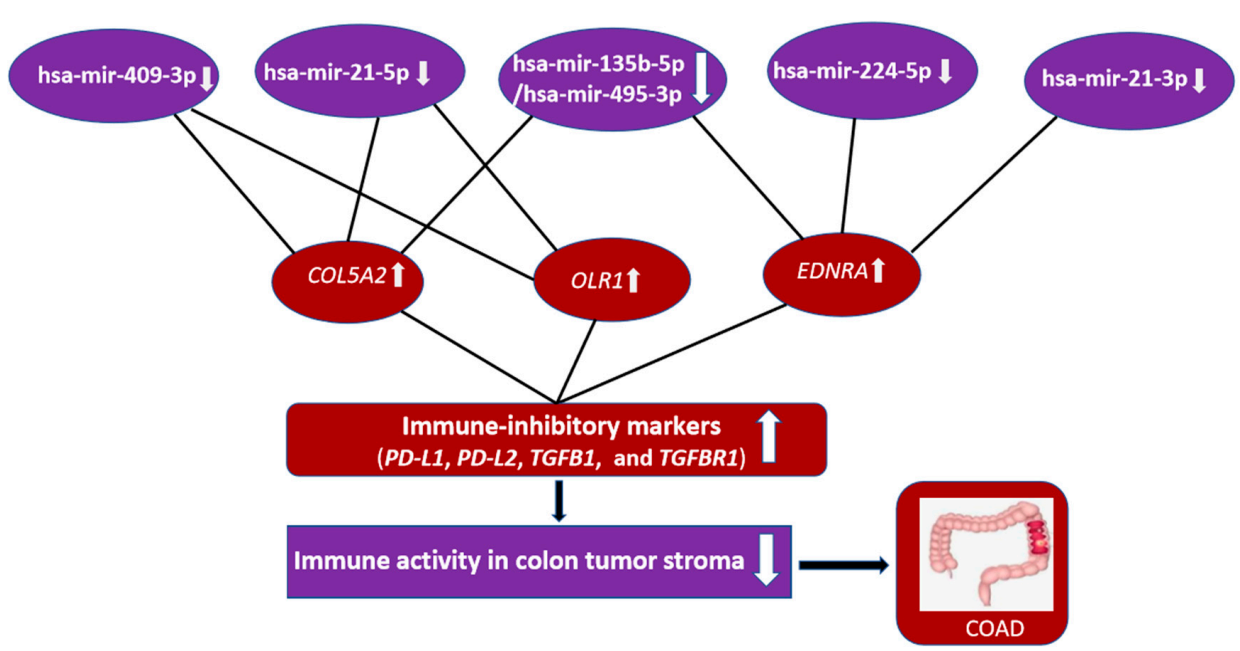

Figure 5. Interaction networks of prognostic hub genes, immune-inhibitory signature genes, and DEmiRs. (A) Interaction network of the three prognostic hub genes (COL5A2, EDNRA, and OLR1) and the marker genes of immune-inhibitory signatures (TAMs, Tregs, and T cell exhaustion). This network was constructed by STRING [26]. TAMs: tumor-associated macrophages. Tregs: regulatory T cells. (B) The miRNA-mRNA regulatory network of the three prognostic hub genes and their DEmiR regulators that may contribute to the pathogenesis of colon cancer. 
Based on the three hub genes and the DEmiRs regulating them, we established an miRNA-mRNA regulatory network that may contribute to the onset and progression of colon cancer. This network included the interactions of hsa-mir-21-5p-COL5A2, hsa-mir-409-3p-COL5A2, hsa-mir-135b-5p/hsamir-495-3p-COL5A2, hsa-mir-21-5p-OLR1, hsa-mir-135b-5p/hsa-mir-495-3p-EDNRA, hsa-mir-21-3pEDNRA and hsa-mir-224-5p-EDNRA (Figure 5B). It suggests that the hsa-mir-21-5p to COL5A2/OLR1, hsa-mir-135b-5p/hsa-mir-495-3p/hsa-mir-409-3p to COL5A2 and hsa-mir-224-5p/hsa-mir-21-3p/hsamir-135b-5p/hsa-mir-495-3p to EDNRA pathways may play substantial roles in regulation of the tumor immune microenvironment in colon cancer.

Our results showed that hsa-miR-21-5p, hsa-mir-21-3p, and hsa-mir-409-3p were downregulated in CTS. However, previous studies revealed that the expression of these miRNAs were upregulated in CRC tissues [44-46]. It suggests that these miRNAs may play distinct roles in CRC and its TME.

A major limitation of this study is that the CTS-associated miRNA-mRNA regulatory network identified by in silico analysis has not been proved by experimental validation. Thus, although our findings could provide potentially useful biomarkers for colon cancer diagnosis and prognosis, as well as therapeutic targets, further experimental and clinical validation is needed to translate these findings into clinical application.

\section{Conclusions}

The identification of transcriptional markers and miRNA-miRNA regulatory networks in CTS may provide new biomarkers for colon cancer diagnosis, prognosis, and treatment, as well as insights into the mechanism of tumor immune microenvironment regulation in colon cancer.

Supplementary Materials: The following are available online at http://www.mdpi.com/2073-4409/8/9/1054/s1, Table S1. Predicted target genes of DEmiRs by miRNet. Table S2. Predicted target genes of DEmiRs by microT-CDS. Table S3. Predicted target genes of DEmiRs by TargetScan. Table S4. 25 KEGG pathways that were significantly associated with the downregulated DEmiRs in CTS. Table S5. 10 KEGG pathways that were significantly associated with the upregulated DEmiRs in CTS. Table S6. Upregulated genes in CTS versus colon normal stroma. Table S7. Downregulated genes in CTS versus colon normal stroma. Table S8. The hub genes (degree $\geq 10$ ) in the protein-protein interaction network of DEGs between CTS and normal stroma. Table S9. Comparisons of the expression levels of eight hub gene between colon tumor stromal fibroblast and normal fibroblast.

Author Contributions: M.N.U. conceived the research, performed data analyses, and wrote the manuscript. M.L. performed data analyses and helped prepare the manuscript. X.W. conceived the research, designed analysis strategies, and wrote the manuscript. All the authors read and approved the final manuscript.

Funding: This work was supported by China Pharmaceutical University (grant numbers 3150120001 and 2632018YX01 to X.W.).

Conflicts of Interest: The authors declare no conflict of interest.

\section{References}

1. Valkenburg, K.C.; de Groot, A.E.; Pienta, K.C. Targeting the tumour stroma to improve cancer therapy. Nat. Rev. Clin. Oncol. 2018, 15, 366-381. [CrossRef] [PubMed]

2. Hanahan, D.; Coussens, L.M. Accessories to the crime: Functions of cells recruited to the tumor microenvironment. Cancer Cell 2012, 21, 309-322. [CrossRef] [PubMed]

3. Bray, F.; Ferlay, J.; Soerjomataram, I.; Siegel, R.L.; Torre, L.A.; Jemal, A. Global cancer statistics 2018: GLOBOCAN estimates of incidence and mortality worldwide for 36 cancers in 185 countries. CA Cancer J. Clin. 2018, 68, 394-424. [CrossRef] [PubMed]

4. Calon, A.; Lonardo, E.; Berenguer-Llergo, A.; Espinet, E.; Hernando-Momblona, X.; Iglesias, M.; Sevillano, M.; Palomo-Ponce, S.; Tauriello, D.V.F.; Byrom, D.; et al. Stromal gene expression defines poor-prognosis subtypes in colorectal cancer. Nat. Genet. 2015, 47, 320-329. [CrossRef] [PubMed]

5. Isella, C.; Terrasi, A.; Bellomo, S.E.; Petti, C.; Galatola, G.; Muratore, A.; Mellano, A.; Senetta, R.; Cassenti, A.; Sonetto, C.; et al. Stromal contribution to the colorectal cancer transcriptome. Nat. Genet. 2015, 47, 312-319. [CrossRef]

6. Uddin, M.N.; Li, M.; Wang, X. Identification of Transcriptional Signatures of Colon Tumor Stroma by a Meta-Analysis. J. Oncol. 2019, 2019, 8752862. [CrossRef] [PubMed] 
7. Cătană, C.-S.; Pichler, M.; Giannelli, G.; Mader, R.M.; Berindan-Neagoe, I. Non-coding RNAs, the Trojan horse in two-way communication between tumor and stroma in colorectal and hepatocellular carcinoma. Oncotarget 2017, 8, 29519-29534. [CrossRef]

8. Bullock, M.D.; Pickard, K.; Mitter, R.; Sayan, A.E.; Primrose, J.N.; Ivan, C.; Calin, G.A.; Thomas, G.J.; Packham, G.K.; Mirnezami, A.H. Stratifying risk of recurrence in stage II colorectal cancer using deregulated stromal and epithelial microRNAs. Oncotarget 2015, 6, 7262-7279. [CrossRef]

9. Hiyoshi, Y.; Schetter, A.J.; Okayama, H.; Inamura, K.; Anami, K.; Nguyen, G.H.; Horikawa, I.; Hawkes, J.E.; Bowman, E.D.; Leung, S.Y.; et al. Increased MicroRNA-34b and -34c Predominantly Expressed in Stromal Tissues Is Associated with Poor Prognosis in Human Colon Cancer. PLoS ONE 2015, 10, e0124899. [CrossRef]

10. Taguchi, Y. Identification of More Feasible MicroRNA-mRNA Interactions within Multiple Cancers Using Principal Component Analysis Based Unsupervised Feature Extraction. Int. J. Mol. Sci. 2016, 17, 696. [CrossRef]

11. Yang, L.; Li, L.; Ma, J.; Yang, S.; Zou, C.; Yu, X. miRNA and mRNA Integration Network Construction Reveals Novel Key Regulators in Left-Sided and Right-Sided Colon Adenocarcinoma. BioMed Res. Int. 2019, 2019, 7149296. [CrossRef] [PubMed]

12. Li, X.; Gill, R.; Cooper, N.G.; Yoo, J.K.; Datta, S. Modeling microRNA-mRNA Interactions Using PLS Regression in Human Colon Cancer. BMC Med. Genom. 2011, 4, 44. [CrossRef] [PubMed]

13. Paul, S.; Lakatos, P.; Hartmann, A.; Schneider-Stock, R.; Vera, J. Identification of miRNA-mRNA Modules in Colorectal Cancer Using Rough Hypercuboid Based Supervised Clustering. Sci. Rep. 2017, 7, 42809. [CrossRef] [PubMed]

14. Sells, E.; Pandey, R.; Chen, H.; Skovan, B.A.; Cui, H.; Ignatenko, N.A. Specific microRNA-mRNA Regulatory Network of Colon Cancer Invasion Mediated by Tissue Kallikrein-Related Peptidase 6. Neoplasia 2017, 19, 396-411. [CrossRef] [PubMed]

15. Izadi, F.; Zamanian-Azodi, M.; Mansouri, V.; Khodadoostan, M.; Naderi, N. Exploring conserved mRNA-miRNA interactions in colon and lung cancers. Gastroenterol. Hepatol. Bed. Bench 2017, 10, 184-193. [PubMed]

16. Pham, V.V.; Zhang, J.; Liu, L.; Truong, B.; Xu, T.; Nguyen, T.T.; Li, J.; Le, T.D. Identifying miRNA-mRNA regulatory relationships in breast cancer with invariant causal prediction. BMC Bioinform. 2019, $20,143$. [CrossRef] [PubMed]

17. Lou, W.; Ding, B.; Xu, L.; Fan, W. Construction of Potential Glioblastoma Multiforme-Related miRNA-mRNA Regulatory Network. Front. Mol. Neurosci. 2019, 12, 66. [CrossRef]

18. Fan, Y.; Siklenka, K.; Arora, S.K.; Ribeiro, P.; Kimmins, S.; Xia, J. miRNet-dissecting miRNA-target interactions and functional associations through network-based visual analysis. Nucleic Acids Res. 2016, 44, W135-W141. [CrossRef]

19. Xia, J.; Gill, E.E.; Hancock, R.E.W. NetworkAnalyst for statistical, visual and network-based meta-analysis of gene expression data. Nat. Protoc. 2015, 10, 823-844. [CrossRef]

20. Pathan, M.; Keerthikumar, S.; Ang, C.-S.; Gangoda, L.; Quek, C.Y.J.; Williamson, N.A.; Mouradov, D.; Sieber, O.M.; Simpson, R.J.; Salim, A.; et al. FunRich: An open access standalone functional enrichment and interaction network analysis tool. Proteomics 2015, 15, 2597-2601. [CrossRef]

21. Vlachos, I.S.; Zagganas, K.; Paraskevopoulou, M.D.; Georgakilas, G.; Karagkouni, D.; Vergoulis, T.; Dalamagas, T.; Hatzigeorgiou, A.G. DIANA-miRPath v3.0: Deciphering microRNA function with experimental support. Nucleic Acids Res. 2015, 43, W460-W466. [CrossRef] [PubMed]

22. Garcia, D.M.; Baek, D.; Shin, C.; Bell, G.W.; Grimson, A.; Bartel, D.P. Weak Seed-Pairing Stability and High Target-Site Abundance Decrease the Proficiency of lsy-6 and Other miRNAs. Nat. Struct. Mol. Biol. 2011, 18, 1139-1146. [CrossRef] [PubMed]

23. Tang, Z.; Li, C.; Kang, B.; Gao, G.; Li, C.; Zhang, Z. GEPIA: A web server for cancer and normal gene expression profiling and interactive analyses. Nucleic Acids Res. 2017, 45, W98-W102. [CrossRef] [PubMed]

24. Mizuno, H.; Kitada, K.; Nakai, K.; Sarai, A. PrognoScan: A new database for meta-analysis of the prognostic value of genes. BMC Med. Genom. 2009, 2, 18. [CrossRef] [PubMed]

25. Li, T.; Fan, J.; Wang, B.; Traugh, N.; Chen, Q.; Liu, J.S.; Li, B.; Liu, X.S. TIMER: A Web Server for Comprehensive Analysis of Tumor-Infiltrating Immune Cells. Cancer Res. 2017, 77, e108-e110. [CrossRef] [PubMed] 
26. Szklarczyk, D.; Gable, A.L.; Lyon, D.; Junge, A.; Wyder, S.; Huerta-Cepas, J.; Simonovic, M.; Doncheva, N.T.; Morris, J.H.; Bork, P.; et al. STRING v11: Protein-protein association networks with increased coverage, supporting functional discovery in genome-wide experimental datasets. Nucleic Acids Res. 2019, 47, D607-D613. [CrossRef] [PubMed]

27. Cotto, K.C.; Wagner, A.H.; Feng, Y.-Y.; Kiwala, S.; Coffman, A.C.; Spies, G.; Wollam, A.; Spies, N.C.; Griffith, O.L.; Griffith, M. DGIdb 3.0: A redesign and expansion of the drug-gene interaction database. Nucleic Acids Res. 2018, 46, D1068-D1073. [CrossRef] [PubMed]

28. Abba, M.; Laufs, S.; Aghajany, M.; Korn, B.; Benner, A.; Allgayer, H. Look who's talking: Deregulated signaling in colorectal cancer. Cancer Genom. Proteom. 2012, 9, 15-25.

29. Nishida, N.; Nagahara, M.; Sato, T.; Mimori, K.; Sudo, T.; Tanaka, F.; Shibata, K.; Ishii, H.; Sugihara, K.; Doki, Y.; et al. Microarray analysis of colorectal cancer stromal tissue reveals upregulation of two oncogenic miRNA clusters. Clin. Cancer Res. 2012, 18, 3054-3070. [CrossRef]

30. Smith, J.J.; Deane, N.G.; Wu, F.; Merchant, N.B.; Zhang, B.; Jiang, A.; Lu, P.; Johnson, J.C.; Schmidt, C.; Bailey, C.E.; et al. Experimentally derived metastasis gene expression profile predicts recurrence and death in patients with colon cancer. Gastroenterology 2010, 138, 958-968. [CrossRef]

31. Freeman, T.J.; Smith, J.J.; Chen, X.; Washington, M.K.; Roland, J.T.; Means, A.L.; Eschrich, S.A.; Yeatman, T.J.; Deane, N.G.; Beauchamp, R.D. Smad4-mediated signaling inhibits intestinal neoplasia by inhibiting expression of $\beta$-catenin. Gastroenterology 2012, 142, 562-571.e2. [CrossRef]

32. Jorissen, R.N.; Gibbs, P.; Christie, M.; Prakash, S.; Lipton, L.; Desai, J.; Kerr, D.; Aaltonen, L.A.; Arango, D.; Kruhøffer, M.; et al. Metastasis-Associated Gene Expression Changes Predict Poor Outcomes in Patients with Dukes Stage B and C Colorectal Cancer. Clin. Cancer Res. 2009, 15, 7642-7651. [CrossRef] [PubMed]

33. Cancer Genome Atlas Network Comprehensive molecular characterization of human colon and rectal cancer. Nature 2012, 487, 330-337. [CrossRef] [PubMed]

34. GEO Accession Viewer. Available online: https://www.ncbi.nlm.nih.gov/geo/query/acc.cgi?acc=GSE46824 (accessed on 24 August 2019).

35. Johnson, W.E.; Li, C.; Rabinovic, A. Adjusting batch effects in microarray expression data using empirical Bayes methods. Biostatistics 2007, 8, 118-127. [CrossRef] [PubMed]

36. Cochran, W.G. The Combination of Estimates from Different Experiments. Biometrics 1954, 10, $101-129$. [CrossRef]

37. Benjamini, Y.; Hochberg, Y. Controlling the False Discovery Rate: A Practical and Powerful Approach to Multiple Testing. J. R. Stat. Soc. Ser. B Methodol. 1995, 57, 289-300. [CrossRef]

38. Paraskevopoulou, M.D.; Georgakilas, G.; Kostoulas, N.; Vlachos, I.S.; Vergoulis, T.; Reczko, M.; Filippidis, C.; Dalamagas, T.; Hatzigeorgiou, A.G. DIANA-microT web server v5.0: Service integration into miRNA functional analysis workflows. Nucleic Acids Res. 2013, 41, W169-W173. [CrossRef] [PubMed]

39. Kanehisa, M.; Furumichi, M.; Tanabe, M.; Sato, Y.; Morishima, K. KEGG: New perspectives on genomes, pathways, diseases and drugs. Nucleic Acids Res. 2017, 45, D353-D361. [CrossRef] [PubMed]

40. Davoli, T.; Uno, H.; Wooten, E.C.; Elledge, S.J. Tumor aneuploidy correlates with markers of immune evasion and with reduced response to immunotherapy. Science 2017, 355, eaaf8399. [CrossRef] [PubMed]

41. Magalhães, L.; Quintana, L.G.; Lopes, D.C.F.; Vidal, A.F.; Pereira, A.L.; D’Araujo Pinto, L.C.; de Jesus Viana Pinheiro, J.; Khayat, A.S.; Goulart, L.R.; Burbano, R.; et al. APC gene is modulated by hsa-miR-135b-5p in both diffuse and intestinal gastric cancer subtypes. BMC Cancer 2018, 18, 1055. [CrossRef] [PubMed]

42. Mullany, L.E.; Wolff, R.K.; Herrick, J.S.; Buas, M.F.; Slattery, M.L. SNP Regulation of microRNA Expression and Subsequent Colon Cancer Risk. PLoS ONE 2015, 10, e0143894. [CrossRef] [PubMed]

43. Chen, S.-M.; Chen, H.-C.; Chen, S.-J.; Huang, C.-Y.; Chen, P.-Y.; Wu, T.-W.E.; Feng, L.-Y.; Tsai, H.-C.; Lui, T.-N.; Hsueh, C.; et al. MicroRNA-495 inhibits proliferation of glioblastoma multiforme cells by downregulating cyclin-dependent kinase 6. World J. Surg. Oncol. 2013, 11, 87. [CrossRef] [PubMed]

44. Kara, M.; Yumrutas, O.; Ozcan, O.; Celik, O.I.; Bozgeyik, E.; Bozgeyik, I.; Tasdemir, S. Differential expressions of cancer-associated genes and their regulatory miRNAs in colorectal carcinoma. Gene 2015, 567, 81-86. [CrossRef] [PubMed]

45. Chang, J.; Huang, L.; Cao, Q.; Liu, F. Identification of colorectal cancer-restricted microRNAs and their target genes based on high-throughput sequencing data. Onco-Targets Ther. 2016, 9, 1787-1794. [PubMed]

46. Wang, Y.; Chen, Z.; Chen, W. Novel circulating microRNAs expression profile in colon cancer: A pilot study. Eur. J. Med. Res. 2017, 22, 51. [CrossRef] [PubMed] 
47. Faltejskova, P.; Svoboda, M.; Srutova, K.; Mlcochova, J.; Besse, A.; Nekvindova, J.; Radova, L.; Fabian, P.; Slaba, K.; Kiss, I.; et al. Identification and functional screening of microRNAs highly deregulated in colorectal cancer. J. Cell Mol. Med. 2012, 16, 2655-2666. [CrossRef] [PubMed]

48. Ji, H.; Chen, M.; Greening, D.W.; He, W.; Rai, A.; Zhang, W.; Simpson, R.J. Deep Sequencing of RNA from Three Different Extracellular Vesicle (EV) Subtypes Released from the Human LIM1863 Colon Cancer Cell Line Uncovers Distinct Mirna-Enrichment Signatures. PLoS ONE 2014, 9, e110314. [CrossRef] [PubMed]

49. Heublein, S.; Albertsmeier, M.; Pfeifer, D.; Loehrs, L.; Bazhin, A.V.; Kirchner, T.; Werner, J.; Neumann, J.; Angele, M.K. Association of differential miRNA expression with hepatic vs. peritoneal metastatic spread in colorectal cancer. BMC Cancer 2018, 18, 201. [CrossRef]

50. Pellatt, D.F.; Stevens, J.R.; Wolff, R.K.; Mullany, L.E.; Herrick, J.S.; Samowitz, W.; Slattery, M.L. Expression Profiles of miRNA Subsets Distinguish Human Colorectal Carcinoma and Normal Colonic Mucosa. Clin. Transl. Gastroenterol. 2016, 7, e152. [CrossRef]

51. Takami, Y.; Russell, M.B.; Gao, C.; Mi, Z.; Guo, H.; Mantyh, C.R.; Kuo, P.C. Sp1 Regulates Osteopontin Expression in SW480 Human Colon Adenocarcinoma Cells. Surgery 2007, 142, 163-169. [CrossRef]

52. Pathi, S.; Jutooru, I.; Chadalapaka, G.; Nair, V.; Lee, S.-O.; Safe, S. Aspirin Inhibits Colon Cancer Cell and Tumor Growth and Downregulates Specificity Protein (Sp) Transcription Factors. PLoS ONE 2012, 7, e48208. [CrossRef] [PubMed]

53. Song, L.-J.; Liu, R.-J.; Zeng, Z.; Alper, S.L.; Cui, H.-J.; Lu, Y.; Zheng, L.; Yan, Z.-W.; Fu, G.-H. Gastrin inhibits a novel, pathological colon cancer signaling pathway involving EGR1, AE2 and P-ERK. J. Mol. Med. 2012, 90, 707-718. [CrossRef] [PubMed]

54. Vázquez-Arreguín, K.; Bensard, C.; Schell, J.C.; Swanson, E.; Chen, X.; Rutter, J.; Tantin, D. Oct1/Pou2f1 is selectively required for colon regeneration and regulates colon malignancy. PLoS Genet. 2019, 15, e1007687. [CrossRef] [PubMed]

55. Taniue, K.; Kurimoto, A.; Takeda, Y.; Nagashima, T.; Okada-Hatakeyama, M.; Katou, Y.; Shirahige, K.; Akiyama, T. ASBEL-TCF3 complex is required for the tumorigenicity of colorectal cancer cells. Proc. Natl. Acad. Sci. USA 2016, 113, 12739-12744. [CrossRef] [PubMed]

56. Li, K.; Guo, Q.; Yang, J.; Chen, H.; Hu, K.; Zhao, J.; Zheng, S.; Pang, X.; Zhou, S.; Dang, Y.; et al. FOXD3 is a tumor suppressor of colon cancer by inhibiting EGFR-Ras-Raf-MEK-ERK signal pathway. Oncotarget 2017, 8 , 5048-5056. [CrossRef]

57. Slattery, M.L.; Herrick, J.S.; Lundgreen, A.; Wolff, R.K. Genetic variation in the TGF- $\beta$ signaling pathway and colon and rectal cancer risk. Cancer Epidemiol. Biomark. Prev. 2011, 20, 57-69. [CrossRef] [PubMed]

58. Mlcochova, J.; Faltejskova, P.; Nemecek, R.; Svoboda, M.; Slaby, O. MicroRNAs targeting EGFR signalling pathway in colorectal cancer. J. Cancer Res. Clin. Oncol. 2013, 139, 1615-1624. [CrossRef]

59. Joo, E.J.; Weyers, A.; Li, G.; Gasimli, L.; Li, L.; Choi, W.J.; Lee, K.B.; Linhardt, R.J. Carbohydrate-Containing Molecules as Potential Biomarkers in Colon Cancer. OMICS 2014, 18, 231-241. [CrossRef]

60. Zhou, X.; Huang, X.; Liang, S.; Tang, S.; Wu, S.; Huang, T.; Mo, Z.; Wang, Q. Identifying miRNA and gene modules of colon cancer associated with pathological stage by weighted gene co-expression network analysis. Onco-Targets Ther. 2018, 11, 2815-2830. [CrossRef]

61. Murdocca, M.; Mango, R.; Pucci, S.; Biocca, S.; Testa, B.; Capuano, R.; Paolesse, R.; Sanchez, M.; Orlandi, A.; di Natale, C.; et al. The lectin-like oxidized LDL receptor-1: A new potential molecular target in colorectal cancer. Oncotarget 2016, 7, 14765-14780. [CrossRef]

62. Rachidi, S.M.; Qin, T.; Sun, S.; Zheng, W.J.; Li, Z. Molecular Profiling of Multiple Human Cancers Defines an Inflammatory Cancer-Associated Molecular Pattern and Uncovers KPNA2 as a Uniform Poor Prognostic Cancer Marker. PLoS ONE 2013, 8, e57911. [CrossRef] [PubMed]

63. Ohtani, H. Focus on TILs: Prognostic significance of tumor infiltrating lymphocytes in human colorectal cancer. Cancer Immun. 2007, 7, 4. [PubMed]

64. Li, B.; Dewey, C.N. RSEM: Accurate transcript quantification from RNA-Seq data with or without a reference genome. BMC Bioinform. 2011, 12, 323. [CrossRef] [PubMed]

65. Lepist, E.-I.; Gillies, H.; Smith, W.; Hao, J.; Hubert, C.; St. Claire, R.L.; Brouwer, K.R.; Ray, A.S. Evaluation of the Endothelin Receptor Antagonists Ambrisentan, Bosentan, Macitentan, and Sitaxsentan as Hepatobiliary Transporter Inhibitors and Substrates in Sandwich-Cultured Human Hepatocytes. PLoS ONE 2014, 9, e87548. [CrossRef] [PubMed] 
66. Lee, H.J.; Hanibuchi, M.; Kim, S.-J.; Yu, H.; Kim, M.S.; He, J.; Langley, R.R.; Lehembre, F.; Regenass, U.; Fidler, I.J. Treatment of experimental human breast cancer and lung cancer brain metastases in mice by macitentan, a dual antagonist of endothelin receptors, combined with paclitaxel. Neuro. Oncol. 2016, 18, 486-496. [CrossRef] [PubMed]

67. Kim, S.-J.; Lee, H.J.; Kim, M.S.; Choi, H.J.; He, J.; Wu, Q.; Aldape, K.; Weinberg, J.S.; Alfred Yung, W.K.; Conrad, C.A.; et al. Macitentan, a dual endothelin receptor antagonist, in combination with temozolomide leads to glioblastoma regression and long-term survival in mice. Clin. Cancer Res. 2015, 21, 4630-4641. [CrossRef]

68. Mullany, L.E.; Herrick, J.S.; Wolff, R.K.; Stevens, J.R.; Samowitz, W.; Slattery, M.L. MicroRNA-transcription factor interactions and their combined effect on target gene expression in colon cancer cases. Genes Chromosomes Cancer 2018, 57, 192-202. [CrossRef] [PubMed]

(C) 2019 by the authors. Licensee MDPI, Basel, Switzerland. This article is an open access article distributed under the terms and conditions of the Creative Commons Attribution (CC BY) license (http://creativecommons.org/licenses/by/4.0/). 